\title{
INEFABILIDAD E INCOMPRENSIBILIDAD DIVINAS EN AGUSTÍN DE HIPONA Y LA TEOLOGÍA NEGATIVA DE MARIO VICTORINO
}

\section{DIVINE INEFFABILITY AND INCOMPREHENSIBILITY IN AUGUSTINE OF HIPPO AND THE NEGATIVE THEOLOGY OF MARIUS VICTORINUS}

\author{
ALEXIA SCHMITT* \\ Dra. en Filosofía \\ Universidad del Salvador - Buenos Aires - Argentina \\ Círculo de Estudios Cusanos de Buenos Aires
}

Artículo recibido el 30 de julio de 2020; aceptado el 30 de octubre de 2020.

*alexiaschmitt8o@hotmail.com

https://orcid.org/oooo-0002-4073-3255

Cómo citar este artículo:

A. Schmitt (2020). "Inefabilidad e incomprensibilidad divinas en Agustín de Hipona y la teología negativa de Mario Victorino" en Palabra y Razón. Revista de Teología, Filosofía y Ciencias de la Religión. No I8 Diciembre 2020, pp 19-38 https://doi.org/I0.29035/pyr.18.19 


\title{
RESUMEN
}

En la primera parte, se profundizará en la concepción agustiniana de "inefabilidad" e "incomprensibilidad" divinas, a fin de mostrar su importancia en su concepción teológica. En la segunda parte, se expondrá la teología negativa de Mario Victorino. Se concluirá señalando tres elementos que constatan la influencia del Victorino sobre la concepción teológica del Hiponense: I) sólo el principio es discernible y definido por su propia existencia, 2) la anterioridad del principio respecto a toda oposición, 3) la docta ignorantia como un modo de conocer más adecuado para aproximarse a la naturaleza divina, que el conocimiento racional.

Palabras claves: Inefabilidad / incomprehensibilidad / teología negativa / docta ignorantia

\begin{abstract}
In the first part, we will develop the Augustinian conception of divine "ineffability" and "incomprehensibility", in order to show the importance of both notions in his theological conception. In the second part, Marius Victorinus 's negative theology will be discussed. We will conclude pointing out three elements that confirm the influence of Victorinus on the theological conception of the Bishop of Hippo: I) only the beginning is discernible and defined by its own existence, 2) the priority of the principle with respect to all opposition, 3) docta ignorantia as a way of knowing more adequate to approach the divine nature, than rational knowledge.
\end{abstract}

Keywords: Ineffability / incomprehensibility / negative theology / docta ignorantia 
Si bien Agustín de Hipona no es considerado estrictamente un representante de la teología negativa, los especialistas han ido descubriendo la importancia que los principios de la apophasis (inefabilidad e incomprensilidad divinas) adquieren para el pensamiento del Africano'. Lossky encuentra elementos de teología negativa en la obra del Hiponense, aunque los considera modestos, en tanto sólo abordaría la temática del ser de Dios como incognoscible para la mente humana ${ }^{2}$. Heiser señala seis pasajes de la obra agustiniana en los cuales la teología negativa cobra relevancia3. Carabine va más allá, al afirmar que los principios de la apophasis constituyen la piedra angular sobre la cual se asienta el pensamiento del Africano ${ }^{4}$.

Así, a lo largo de toda la obra de Agustín y en diversos contextos, la advertencia de la inefabilidad e incomprensibilidad divinas es constante ${ }^{5}$. Queda entonces abierta la cuestión sobre las fuentes neoplatónicas que habrían alimentado el pensamiento del Hiponense en este punto. Teniendo en cuenta el hecho que el joven Agustín se convierte al cristianismo tras la lectura de ciertos "libros de los platónicos" traducidos al latín por Mario Victorino, surge naturalmente la pregunta de si y en qué medida la teología negativa del célebre Rétor podría haber influido sobre el pensamiento agustiniano en este punto.

Los especialistas continúan hasta hoy debatiendo si la obra del Victorino influye sobre el pensamiento agustiniano, pero tan sólo tienen en cuenta sus doctrinas trinitarias. Un primer grupo descarta toda influencia decisiva. Schmid advierte el contexto heresiológico y el carácter eclesiástico de la enseñanza trinitaria agustiniana ${ }^{7}$. Siguiendo

I Si bien teología negativa y apofatismo no son equivalentes (Cf. P. Hadot, "Apofatismo y teología negativa“, en P Hadot, Ejercicios espirituales y filosofía antigua, pp. 19I-200, Siruela, Madrid, 2006), adoptamos en el presente artículo la posición de Lossky, quien otorga a la teología negativa un sentido más amplio que el tradicional, en tanto considera no se trata de una vía exclusiva para aquellos pensadores que conciben a Dios por sobre el ser, sino en la cual se podría incluir a todo pensamiento religioso en la medida en que toma consciencia de la trascenencia divina y recurre a la negación a fin de advertir Su inaccesibilidad, culminando así en un nuevo modo de conocer, que va más allá del saber racional (cf. V. Lossky, "Les éléments de Théologie négative dans la pensée de saint Augustin", en Augustinus Magister I (1954), pp. 575-58I: p. 575).

2 Cf. V. Lossky, "Les éléments de Théologie négative dans la pensé de saint Augustin", p. 575.

3 Cf. J. Heiser, "Saint Augustine and Negative Theology", en New Scholasticism 63 (1989), pp. 66-80.

4 Cf. D. Carabine, The Unknown God: Negative theology in the platonic tradition: Plato to Eriugena, chap. 9: "Saint Augustine: a negative theology?", pp. 259-278, Peeters press, Louvain, 1995.

5 Véase por ejemplo De ordine II, I6, 44; De ordine II, I8, 47; Conf. I, 4, 4; Conf. I, 6, IO; De Trin. V, I, 2; De Trin. V, 2, 3; De Trin. XV, 2, 2; Sermo II7, 2, 3; Sermo II7, 3, 5; Ep. I99, I3, 52.

6 Conf. VII, 9, I3. Sobre el debate actual concerniente a cuáles serían estos "libros platónicos", véase: P. F. Beatrice, "Quosdam Platonicorum Libros. The Platonic Reading of Augustine in Milan", Virgiiliae Christianae 43 (1989), pp. 248-28I.

7 Cf. R. Schmid, Marius Victorinus Rhetor und seine Beziehungen zu Augustin, Diss. Theol., p. II y pp. 
la advertencia de Schmid, Hadot precisa: "una distancia inmensa separa a Agustín de Victorino (...): para este la teología trinitaria es un discurso teogónico, para Agustín es un ejercicio espiritual del yo, que descubre la imagen de la Trinidad en el retorno del alma sobre ella misma".

Entre los estudiosos que señalan la influencia del Rétor sobre la obra agustiniana, encontramos a Henry. Si bien su principal preocupación es mostrar la relación entre la obra plotiniana con la del Victorino, -resalta los elementos plotinianos que pueden encontrarse en el pensamiento del Africano, pero a la vez advierte una diferencia fundamental entre ambos, en tanto el Rétor defiende el dogma de la consubstancialidad"9-, precisamente por defender la consubstancialidad, Henry afirma: "el Adversus Arium de Victorino prepara el camino para el De Trinitate de Agustín" ${ }^{\text {Io }}$ Por su parte, Cipriani ha señalado que en los diálogos de Casicíaco se encuentran huellas de la influencia de los comentarios paulinos de Mario Victorino, particularmente, en la doctrina trinitaria y la formulación de la fe cristiana"

En una posición intermedia se encuentran aquellos que admiten la influencia del Victorino sobre el pensamiento agustiniano, aunque ésta resultaría suavizada por diferentes razones. Clark destaca el diferente modo en que cada uno entiende la doctrina cristiana del hombre creado a imagen de $\operatorname{Dios}^{12}$. La razón de esta diferencia radicaría en la previa asimilación por parte del Hiponense de la doctrina de la imagen de Ambrosio. En palabras de la agustinóloga:

Podemos entonces decir que si, de hecho, luego de su conversión Agustín se familiarizó con los tratados trinitarios de Mario Victorino, los leyó con una mente previamente formada por Ambrosio. La aceptación de Agustín de la doctrina de la imagen de Ambrosio resulta clara desde las afirmaciones en el De Trinitate de Agustín, aunque no mencione aquí el nombre de Ambrosio. Esta podría ser la razón por la cual no encontramos ninguna evidencia llamativa en

I7-I8, Kiel, I895.

8 P. Hadot, Porphyre et Victorinus, I, p. 478, Études Augustiniennes, Paris, 1968.

9 Cf. P. Henry, "The Adversus Arium of Marius Victorinus, the first systematic exposition of the doctrine of the Trinity", en Journal of theological studies, t. I, I950, pp. 42-55.

Io P. Henry, "The Adversus Arium of Marius Victorinus, the first systematic exposition of the doctrine of the Trinity", p. 52.

II Cf. N. Cipriani, "Agustín, lector de los comentarios paulinos de Mario Victorino", en Augustinus 56, 222 (20II), pp. 425-44I.

I2 Cf. M. T. Clark, "Victorinus and Augustine: some differences", en Augustinian studies XVII (I986), pp. I47-I59: pp. I53-I58. 
el De Trinitate de Agustín de su dependencia del Victorino ${ }^{13}$.

García Bazán por su parte señala que el Obispo de Hipona atenúa los elementos platónicos contenidos en la doctrina del Rétor a fin de volverlo compatible con el dogma cristiano:

San Agustín ha podido utilizar los materiales alusivos provenientes de platónicos como Numenio y Plotino y de un platónico cristiano que ha abrevado en fuentes teúrgicas y gnósticas, como Mario Victorino, pero rebajándolos del alto voltaje de sus consideraciones metafísicas para poder dócilmente darles la forma cristiana ${ }^{\text {I4 }}$.

Teniendo en cuenta la relevancia que los principios de la apophasis cobran en el enfoque del pensamiento agustiniano de Carabine ${ }^{15}$, y que todos los estudios realizados hasta el momento sobre la posible influencia de la obra del Victorino en la del Hiponense se centran fundamentalmente en sus doctrinas trinitarias, consideramos un aporte legítimo profundizar en la concepción agustiniana de "incomprensibilidad" e "inefabilidad" divinas, y en la teología negativa del Rétor, a fin de establecer si puede afirmarse (y de ser así, en qué medida) la influencia del Victorino sobre la reflexión del Hiponense en este punto.

\section{Inefabilidad e incomprensibilidad divinas en Agustín}

Gilson comienza el capítulo cuarto de su célebre Introducción, dedicado a la imagen de Dios, con la siguiente advertencia: "lo que el alma sabe de la manera más clara, después de haber tratado de aprehender a Dios, es cómo ella lo ignora"16. Carabine va más allá al afirmar que la incognoscibilidad de la naturaleza divina yace en el corazón de la especulación teológica agustiniana ${ }^{17}$.

Sin pretender agotar la riqueza del pensamiento del Obispo de Hipona sobre este punto, tres advertencias interrelacionadas nos han parecido las fundantes: I) Dios resulta para el hombre inefable ya que 2) el hombre nunca podrá llegar a comprehender la naturaleza divina, 3) en

I3 M. T. Clark, "Victorinus and Augustine: some differences", p. 159.

I4 F. García Bazán, "Sobre la Trinidad y las tríadas en San Agustín y Mario Victorino", en M. E. Sacchi (ed.), Ministerium Verbi. Estudios dedicados a Monseñor Héctor Aguer en ocasión del XXV aniversario de su ordenaión sacerdotal, pp. 315-329: p. 329, Basilea, Buenos Aires, 1997.

I5 Cf. D. Carabine, The Unknown God, chap. 9: "Saint Augustine: a negative theology?", pp. 259-278. I6 É. Gilson, Introduction à l'étude de Saint Augustine, cap. IV, p. 286, Troisième édition, Vrin, Paris, 1949.

I7 Cf. D. Carabine, The Unknown God, p. 267. 
tanto Dios es el mismo ser, y por ende, carente de toda determinación. Profundicemos en cada una de estas advertencias.

\section{I) Inefabilidad divina}

Agustín resalta en numerosas ocasiones la inefabilidad divina ${ }^{18}$, llevándola incluso hasta sus últimas consecuencias en De doctrina christiana; la inadecuación radical entre toda palabra humana y la excelencia de Dios vuelve al hombre incapaz incluso de expresar la inefabilidad divina sin caer en una contradicción:

Tampoco debe denominarse a Dios inefable, pues, cuando esto se dice, algo se dice. No sé qué lucha de palabras existe, porque si es inefable lo que no puede ser expresado, no será inefable lo que puede llamarse inefable. Esta contienda de voces más bien debe ser acallada con el silencio que apaciguada con las palabras. Sin embargo, Dios, aunque de Él no podamos decir cosa alguna, escucha la ofrenda de nuestra voz y quiere nos alegremos con nuestras voces dirigidas en alabanza de Él. De aquí procede que se le llame Dios. Ciertamente que no se le conoce por el ruido de estas dos sílabas $D e-u s$, pero los conocedores de la lengua latina, al percibir sus oídos este sonido, los excita a pensar en una naturaleza excelentísima e inmortal ${ }^{19}$.

Como señala Carabine, el final de la cita resulta clave para entender el pensamiento de Agustín sobre este punto:

La última línea del texto citado es, creo, la clave para comprender el pensamiento de Agustín: la naturaleza inefable de Dios debe de hecho dejarse sin pronunciar y, sin embargo, como todos los seguidores de la vía negativa, Agustín advierte que la naturaleza humana debe tener algún medio para expresar lo inefable. Esta es la observación aparentemente contradictoria que se encuentra en el corazón de toda teología negativa. La continua utilización de Agustín del término "inefable" es un recordatorio constante de que, si bien no puede decirse nada digno de la naturaleza divina, no obstante, las palabras son

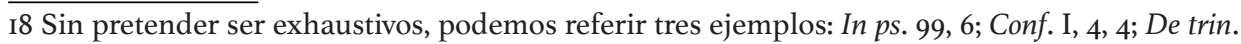
$\mathrm{XV}, 27,50$.

I9 De doctrina christiana I, 6: Ac per hoc ne ineffabilis quidem dicendus est Deus, quia et hoc cum dicitur, aliquid dicitur. Et fit nescio qua pugna verborum, quoniam si illud est ineffabile quod dici non potest, non est ineffabile quod vel ineffabile dici potest. Quae pugna verborum silentio cavenda potius quam voce pacanda est. Et tamen Deus, cum de illo nihil digne dici possit, admisit humanae vocis obsequium, et verbis nostris in laude sua gaudere nos voluit. Nam inde est et quod dicitur Deus. Non enim revera in strepitu istarum duarum syllabarum ipse cognoscitur, sed tamen omnes latinae linguae scios, cum aures eorum sonus iste tetigerit, movet ad cogitandam excellentissimam quamdam immortalemque naturam. Cf. V. Lossky, "Les éléments de Théologie négative dans la pensé de saint Augustin", en Augustinus Magister I (1954), p. 578. 
necesarias para indicar la dirección correcta ${ }^{20}$.

A pesar de reconocer la inefabilidad de la naturaleza divina, el Obispo de Hipona no se resigna en su búsqueda. El hombre estaría condenado al silencio si no fuera capaz de reconocer en toda creatura la huella del principio, del cual han recibido su ser; en palabras de Gilson: "La única vía que permanece abierta al hombre para elevarse al conocimiento de Dios pasa pues por la consideración de sus efectos"21. El Hiponense debe entonces, según el mencionado especialista, mantener un difícil equilibrio en cuanto al lenguaje que utiliza, evitando ambos extremos:

creer que nada de lo que sabemos de las cosas no puede en ningún sentido ser afirmado de Dios, y creer que lo que sabemos de las cosas puede ser afirmado de Dios en el mismo sentido que lo que afirmamos de las cosas. En realidad, la distancia que separa al Creador de la creatura es inmensa, y sin embargo, no es en vano que empleemos palabras que designan creaturas para hablar de su Creador ${ }^{22}$.

En consecuencia, en el pensamiento del Africano ambas teologías, la afirmativa y la negativa, conviven y se complementan. De ahí que en la siguiente cita Agustín pueda simultáneamente resaltar que Dios es nada de los entes finitos, en tanto su naturaleza infinita es por sobre toda limitación y determinación; pero a la vez, para las creaturas, Dios es todo, en tanto causa primera, conservadora y final:

Si atiendes a lo visible, Dios no es pan, tampoco es agua, tampoco es esta luz, tampoco es vestido, tampoco es casa. Todo esto, en efecto, es visible y cada cosa es sólo lo que es: lo que es pan no es agua, lo que es vestido no es casa, ni lo que son estas cosas es Dios, pues son visibles. Para ti Dios es todo: si tienes hambre es tu pan; si tienes sed es tu agua; si estás en tinieblas es tu luz, porque permanece incorruptible; si estás desnudo es tu vestido de inmortalidad (...). Todo puede decirse de Dios, mas de Dios nada se dice dignamente. Nada más vasto que esta penuria. Buscas un nombre adecuado: no lo hallas; buscas hablar de él en cualquier modo: hallas todo ${ }^{23}$.

20 D. Carabine, The Unknown God, p. 263.

2I É. Gilson, Introduction à l'étude de Saint Augustine, p. 287. Cf. De trin. V 8, 9.

22 É. Gilson, Introduction à l'étude de Saint Augustine, p. 287.

23 In Ioh. evang. XIII, 5: Si visibilia attendis, nec panis est Deus, nec aqua est Deus, nec lux ista est Deus, nec vestis est Deus, nec domus est Deus. Omnia enim haec visibilia sunt, et singula sunt: quod est panis, non hoc est aqua; et quod est vestis, non hoc est domus; et quod sunt ista, non hoc est Deus: visibilia enim sunt. Deus tibi totum est: si esuris, panis tibi est; si sitis, aqua tibi est; si in tenebris es, lumen tibi est, quia incorruptibilis manet; si nudus es, immortalitatis vestis tibi est (...). Omnia possunt dici de Deo, et nihil 
Por tanto, si bien es lícito predicar de Dios las perfecciones que encontramos en las creaturas pues de Él las han recibido, tales cualidades no deben entenderse en el mismo sentido respecto de la naturaleza divina. Mientras en la creatura las perfecciones se distinguen de su ser y entre sí, pues son participadas, en Dios se identifican, constituyen su mismo ser. Con estas palabras lo advertía nuestro Pensador:

Por tanto, no encontrarás cosa mejor que puedas decir de Él sino bueno es el Señor, si comprendes perfectamente el bien por el cual son buenas todas las demás cosas. Todas las cosas buenas las hizo Él; pero Él es bueno a quien nadie hizo. Él es bueno por su propio bien, no por participación de otro bien. Él es el bien por su mismo bien, sin adherirse a otro bien ${ }^{24}$.

Pero la razón última por la cual todo nombre resulta inadecuado para referir a la naturaleza divina es la diferencia ontológica insalvable entre las creaturas y Dios, al cual, por ende, no pueden aplicársele las diez categorías de Aristóteles:

Todo cuanto se afirme de esta naturaleza inconmutable, invisible, vida suma y que a sí misma se abasta, no ha de medirse con el compás de las cosas mudables, perecederas e indigentes. (...) Porque, ¿cómo podrá el hombre comprender con su inteligencia a Dios, si aún no comprende su inteligencia, con la que quiere comprenderlo? Y si la comprende, advierta con diligencia cómo no hay en su naturaleza nada mejor, y observe si descubre allí la línea de sus formas, la belleza de sus colores, su magnitud espacial, la distancia de sus partes, la extensión de su mole, sus movimientos en el espacio y otros detalles semejantes. Nada de esto encontramos en lo que hay de mejor en nosotros, es decir, en nuestra inteligencia, con la que nos adueñamos de la sabiduría en la medida de nuestra capacidad. Pues lo que no descubrimos en nuestra parte más noble no hemos de buscarlo en aquel que es infinitamente superior a lo más excelso de nuestro ser ${ }^{25}$.

digne dicitur de Deo. Nihil latius hac inopia. Quaeris congruum nomen, non invenis; quaeris quoquo modo dicere, omnia invenis.

24 In ps. 134, 3: non invenis melius quod de illo dicas, nisi quia bonus est Dominus: si tamen intellegas proprie bonum, a quo sunt caetera bona. Omnia enim bona ipse fecit: ipse est bonus quem nemo fecit. Ille bono suo bonus est, non aliunde participato bono: ille seipso bono bonus est, non adhaerendo alteri bono. Cf. De trin. VI, 4, 6; VI, IO, II; XV, 5, 7.

25 De Trin. V, I, 2: ea quae de natura incommutabili et invisibili summeque vivente ac sibi sufficiente dicuntur, non ex consuetudine visibilium atque mutabilium et mortalium vel egenarum rerum esse metienda. (...) Nam quo intellectu homo Deum capit qui ipsum intellectum suum quo eum vult capere nondum capit? Si autem hunc iam capit, attendat diligenter nihil eo esse in sua natura melius, et videat utrum ibi videat ulla lineamenta formarum, nitores colorum, spatiosam granditatem, partium distantiam, molis distensionem, aliquas per locorum intervalla motiones, vel quid eiusmodi. Nihil certe istorum invenimus in eo, quo in natura nostra nihil melius invenimus, id est, in nostro intellectu, quo sapientiam capimus quantae capaces sumus. Quod ergo non invenimus in meliore nostro, non debemus in 
Siguiendo a la tradición neoplatónica, los términos negativos resultan los más apropiados para referirnos a la naturaleza divina, ya que nos permiten resaltar su trascendencia sin circunscribir su esencia. Incluso el Hiponense llega a afirmar respecto de Dios ambos opuestos, poniéndolos a veces en su forma superlativa, insinuando así la advertencia de la anterioridad del principio a los opuestos, que desarrolla más sistemáticamente el Victorino, según veremos: “QQué es, pues, mi Dios? (...) ocultísimo y presentísimo, (...) inmutable que todo lo mudas, nunca nuevo y nunca viejo, siempre en actividad, siempre en reposo"26. En particular retengamos la identidad en Dios de actividad y reposo, pues veremos que el Rétor realiza la misma advertencia.

\section{2) Incomprehensibilidad divina}

Dios permanece inefable para el hombre ya que escapa a toda categoría y concepto humano; en este sentido Dios resulta para nosotros incomprensible ${ }^{27}$. Pero la razón última de la incomprensibilidad divina no se encuentra en una deficiencia de nuestro conocer, sino que, como adelantábamos, es de orden ontológico: Dios es el ser verdadero, porque es el único inmutable y eterno. En palabras del Hiponense:

Todas las demás substancias o esencias son susceptibles de accidentes, y cualquier mutación, grande o pequeña, se realiza con su concurso; pero en Dios no cabe hablar de accidentes; y, por ende, sólo existe una substancia o esencia inconmutable, que es Dios, a quien con suma verdad conviene el ser, de donde se deriva la palabra esencia. Todo cuanto se muda no conserva el ser; y cuanto es susceptible de mutación, aunque no varíe, puede ser lo que antes no era; y, en consecuencia, sólo aquel que no cambia ni puede cambiar es, sin escrúpulo, verdaderamente el Ser ${ }^{28}$.

Enseguida profundizaremos en el status ontológico de la naturaleza divina. Antes detengámonos en un pasaje en el cual el Hiponense

\footnotetext{
illo quaerere, quod longe melius est meliore nostro.

26 Conf. I, 4, 4: Quid es ergo Deus meus? (...) secretissime et praesentissime, (...) immutabilis mutans omnia, numquam novus, numquam vetus (...) semper agens, semper quietus. Cf. Conf. XIII, 37, 52: Tu autem, Domine, semper operaris et semper requiescis; In Io. ev. XVII, I4 y San Agustín, Confesiones, traducción, notas e introducción G. Piemonte, nota I462, p. 434.

27 Véase por ejemplo Conf. I, 4, 4; Sol. I, I3, 23; De trin. I, 2, 4.

28 De Trin. V, 2, 3: Sed aliae quae dicuntur essentiae, sive substantiae capiunt accidentias quibus in eis fiat vel magna vel quantacumque mutatio; Deo autem aliquid eiusmodi accidere non potest. Et ideo sola est incommutabilis substantia vel essentia, quae Deus est, cui profecto ipsum esse, unde essentia nominata est, maxime ac verissime competit. Quod enim mutatur, non servat ipsum esse; et quod mutari potest, etiamsi non mutetur, potest quod fuerat non esse; ac per hoc illud solum quod non tantum non mutatur, verum etiam mutari omnino non potest, sine scrupulo occurrit quod verissime dicatur esse. Cf. De moribus ecclesiae XIV, 24.
} 
advierte que, paradójicamente, sólo podemos saber lo que no es Dios, y que tal saber negativo supone haber reconocido la trascendencia divina:

Si ahora no podéis comprender qué es Dios, comprended al menos qué no es. Mucho tendréis adelantado si no pensáis de Dios algo distinto de lo que Él es. ¿No puedes llegar aún a lo que Él es? Llega a lo que no es. Dios no es cuerpo, no es la tierra, no es el cielo, no es la luna, no es el sol, no es las estrellas; no es eso corporal, ya que, si no es lo celeste, jcuánto menos lo terreno! Elimina todo cuerpo. Oye aún otra cosa: Dios no es un espíritu mudable. (...) si no eres capaz de comprender qué es Dios, no supongas que es poco para ti saber qué no $\mathrm{es}^{29}$.

Este texto nos exhorta a abandonar las realidades sensibles e inteligibles; esto es, toda realidad mudable y contingente. Sólo así podremos alcanzar el máximo saber de Dios que el hombre es capaz: una docta ignorantia. Paradójicamente esta ignorancia resulta más "sabia" que la pretensión de comprender a Dios con nuestros conceptos y categorías. Con estas palabras lo advertía en un sermón:

Tal ignorancia es más reverente, que una ciencia presuntuosa. (...) Estamos hablando de Dios, ¿qué tiene de extraño que no lo comprendas? Pues, si lo comprendes, no es Dios. Antepón la piadosa confesión de tu ignorancia a una temeraria profesión de ciencia. Tocar en alguna medida a Dios con la mente es una gran dicha; en cambio, comprehenderlo es absolutamente imposible ${ }^{30}$.

De manera semejante, en una carta, señala: "Me parece que yerra, no el que reconoce su ignorancia, sino el que se imagina saber lo que no sabe"31. Hacia el final de ésta, él mismo se presenta como ignorante: quien confiese su ignorancia no sólo evita cualquier posible error pues "ni afirma ni niega" 32 nada, sino que se muestra más sabio que aquel que no ha reconocido la trascendencia divina, -y por ende, no respeta

29 In Ioh. evang. 23, 9-IO: Nunc si non potestis comprehendere quid sit Deus, vel hoc comprehendite quid non sit Deus: multum profeceritis, si non aliud quam est, de Deo senseritis. Nondum potes pervenire ad quid sit, perveni ad quid non sit. Non est Deus corpus, non terra, non coelum, non luna, non sol, non stellae, non corporalia ista. Si enim non coelestia, quanto minus terrena? Tolle omne corpus. Adhuc audi aliud: non est Deus mutabilis spiritus.(...) id est, ut si non vales comprehendere Deus quid sit, parum non tibi putes esse scire quid non sit.

30 Sermo II7, 3, 5: Magis pia est talis ignorantia, quam praesumpta scientia. Loquimur enim de Deo. (...) De Deo loquimur, quid mirum si non comprehendis? Si enim comprehendis, non est Deus. Sit pia confessio ignorantiae magis, quam temeraria professio scientiae. Attingere aliquantum mente Deum; magna beatitudo est; comprehendere autem, omnino impossibile.

3I Ep. 199, 13, 52: error quidem in utroque vitandus est, quantum ab homine vitari potest, sive citius sive tardius quam futurum est, Dominus venturus esse credatur; sed mihi quisquam non videtur errare, cum aliquid nescire se scit, sed cum se putat scire quod nescit.

32 Ep. 199, 13, 54: nihil eorum aut affirmat aut negat. 
su incomprensibilidad e inefabilidad procurando aplicarle categorías, conceptos y nombres humanos, -sólo legítimos para las creaturas. Recordemos asimismo esta oración de Confessiones: "que ame hallarte no encontrando, más bien que encontrando no hallarte" 33 .

En De ordine advierte el alcance limitado del conocer humano, el cual, teniendo en cuenta que no puede comprender qué es el espacio, el tiempo, y demás condiciones que limitan el modo de existir de las creaturas sensibles, menos será capaz de llegar al conocimiento del alma humana o Dios, cuyas naturalezas trascienden dichas limitaciones; de ahí que se afirme que la mejor manera de conocer tales naturalezas sea ignorando, es decir, sin pretender definirlas ni delimitarlas:

el que vive esclavizado de los apetitos, sediento de las cosas transitorias, o también el que se ha libertado ya de ese cautiverio y vive en continencia, pero no sabe lo que es la nada, la materia informe, lo que está formado y no tiene alma, el cuerpo y la forma en el cuerpo, el espacio y el tiempo, la localización y la temporalidad; el que ignora qué es el movimiento local y el cambio, el movimiento estable y la inmortalidad; el que no tiene idea de lo que es trascender todo lugar y todo tiempo y existir siempre, lo que es no hallarse en ninguna parte, siendo inmenso ni encerrado en ningún límite de tiempo, siendo eterno; quien no sepa esto y se mete a investigar, no la naturaleza de Dios, a quien se conoce mejor ignorando, sino la naturaleza de la misma alma, caerá en toda clase de errores ${ }^{34}$.

Un poco más adelante señala que tal orden de los estudios culmina en un sabio reconocimiento de nuestra ignorante frente a la naturaleza infinita de Dios:

He aquí el orden de los estudios de la sabiduría con que el hombre se capacita para entender el orden de las cosas, es decir, para discernir los dos mundos y al mismo padre del universo, del cual ninguna ciencia hay en el alma, si no se sabe, cómo no se lo conoce" 35 .

33 Conf. I, 6, I0: amet non inveniendo invenire potius quam inveniendo non invenire.

34 De ord. II, I6, 44: Quisquis autem vel adhuc servus cupiditatum, et inhians rebus pereuntibus, vel iam ista fugiens casteque vivens, nesciens tamen quid sit nihil, quid informis materia, quid formatum exanime, quid corpus, quid exanime in corpore, quid locus, quid tempus, quid in loco, quid in tempore, quid motus secundum locum, quid motus non secundum locum, quid stabilis motus, quid sit aevum, quid sit nec in loco esse, nec nusquam, et quid sit praeter tempus et semper, quid sit et nusquam esse et nusquam non esse, et numquam esse et nunquam non esse: quisquis ergo ista nesciens, non dico de summo illo Deo, qui scitur melius nesciendo, sed de anima ipsa sua quaerere ac disputare voluerit, tantum errabit quantum errari plurimum potest. Cf. V. Lossky, "Les éléments de Théologie négative dans la pensé de saint Augustin", pp. 576-577.

35 De ord. II, I8, 47: Hic est ordo studiorum sapientiae, per quem fit quisque idoneus ad intellegendum 
En De Trinitate, comentando los versículos "Alégrese el corazón de los que buscan al Señor; (...) buscad siempre su rostro"36, se pregunta: "Parece que jamás se encuentra lo que siempre se busca: ¿cómo, pues, ha de alegrarse y no sentir tristeza el corazón de los que buscan, si no pueden encontrar lo que buscan?"37. No es que no se encuentre nunca lo que se busca, sino que, a medida que vamos conociendo realidades "incomprensibles" como Dios, nos damos cuenta cuánto nos superan ${ }^{38}$.

Podemos entonces concluir este segundo punto: la negación como forma legítima de aproximarse a la naturaleza divina y su culminación en una "docta ignorantia" constatan la influencia de la teología negativa proveniente de la tradición neoplatónica, -en particular, de Plotino-, en la obra del Hiponense.

\section{3) Dios: el mismo ser}

Habíamos dejado pendiente profundizar en el status ontológico de la naturaleza divina. La naturaleza divina, eterna e inmutable, resulta incomprensible para nuestras categorías y conceptos, sólo apropiados para las creaturas:

No son una cosa los años de Dios y otra el mismo Dios, sino que los años de Dios son la eternidad de Dios; y su eternidad es su misma sustancia, la cual nada tiene de mutable; allí nada hay pretérito, como que ya no existe; nada hay futuro, como si todavía no es. Allí no hay más que el presente: existe, es. En él no hay ni el "fue", ni el "será", porque el "fue", ya no es; y el "será", todavía no es; sino que lo que en Dios hay es únicamente el "es". (...) Ya veis aquí el gran Es. ¡Sí, sublime Es! Ante esto, ¿qué es el hombre? Ante tan sublime Es, ¿qué es el hombre, por grande que sea? ¿Quién aprehenderá aquel "ser"?, ¿quién participará de él?, ¿quién podrá alcanzarlo, o participar de él?, ¿quién pretenderá poder estar en él?39

ordinem rerum, id est ad dignoscendos duos mundos et ipsum parentem universitatis, cuius nulla scientia est in anima, nisi scire quomodo eum nesciat.

36 Sal. I04, 3-4.

37 De Trin. XV, 2, 2: Videtur enim, quod semper quaeritur, numquam inveniri: quomodo iam laetabitur, et non potius contristabitur cor quaerentium, si non potuerint invenire quod quaerunt?

38 Cf. De Trin. XV, 2, 2: Si ergo quaesitus inveniri potest, cur dictum est: Quaerite faciem eius semper? An et inventus forte quaerendus est? Sic enim sunt incomprehensibilia requirenda, ne se existimet nihil invenisse, qui quam sit incomprehensibile quod quaerebat, potuerit invenire. Cur ergo sic quaerit, si incomprehensibile comprehendit esse quod quaerit, nisi quia cessandum non est, quamdiu in ipsa incomprehensibilium rerum inquisitione proficitur, et melior meliorque fit quaerens tam magnum bonum, quod et inveniendum quaeritur, et quaerendum invenitur?

39 In ps. IOI, ii, IO: Non enim aliud anni Dei, et aliud ipse: sed anni Dei, aeternitas Dei est: aeternitas, ipsa Dei substantia est, quae nihil habet mutabile; ibi nihil est praeteritum, quasi iam non sit; nihil est futurum, quasi nondum sit. Non est ibi nisi: Est; non est ibi: Fuit et erit; quia et quod fuit, iam non est; et 
Pero como se desprende del comienzo de la cita anterior, - "No son una cosa los años de Dios y otra el mismo Dios, sino que los años de Dios son la eternidad de Dios; y su eternidad es su misma sustancia"-, tal inmutabilidad y eternidad constituyen en realidad dos aspectos derivados de la condición ontológica única divina, que Gilson ha sabido descubrir muy bien a partir de la sentencia de De moribus ecclesiae: "Deum nihil aliud dicam esse nisi idipsum esse"40 (de Dios sólo podemos decir que es). A partir de esta fórmula, nuestro especialista concluye: "No hay definición de Dios, puesto que es el mismo ser, sustraído a toda determinación" ${ }^{4}$. Detengámonos a analizar la mencionada sentencia: de Dios sólo podemos decir que es.

Esta fórmula destaca a la vez la simplicidad y la plenitud del ser de Dios. El principio escapa a toda determinación, pues, como advertía en De civitate Dei, en Dios "no es una cosa la cualidad y otra la sustancia (...) lo que tiene, eso mismo es"42.

Por otra parte ya habíamos señalado que sólo de Dios podemos decir que es verdaderamente, pues, a diferencia de las creaturas que reciben su ser y por ende son mudables, finitas y contingentes, Dios carece de todo no-ser: eterno, inmutable, perfecto.

Para concluir esta primera parte, Agustín retoma de la tradición neoplatónica la advertencia de la plenitud y simplicidad del ser de Dios. Sin embargo, la expresa mediante fórmulas positivas: Dios es el ser verdadero; de Dios sólo podemos decir que es.

\section{La teología negativa de Mario Victorino}

En su traducción de Confessiones, Piemonte advierte que la interrogación inicial del libro primero por la quididad de $\operatorname{Dios}^{43}$ retomaría las del Rétor en Ad Candidum. Sin embargo, según Hadot, el párrafo más extenso que el Victorino consagra a la teología negativa se encuentra en Adversus

quod erit, nondum est: sed quidquid ibi est, nonnisi est. (...) Magnum ecce Est, magnum Est! Ad hoc homo quid est? Ad illud tam magnum Est, homo quid est, quidquid est? Quis apprehendat illud esse? quis eius particeps fiat? quis anhelet? quis aspiret? quis ibi se esse posse praesumat?

40 Ag., De moribus ecclesiae I, XIV, 2. Cf. É. Gilson, Introduction à l'étude de Saint Augustine, pp. 285-286.

4I É. Gilson, Introduction à l'étude de Saint Augustine, p. 286.

$42 \mathrm{Ag} .$, De civ. Dei XI, Io, 3: non aliud est in eis qualitas, aliud substantia (...) quae habet, haec et est, et ea omnia unus est. Cf. De Trin. V, 2, 3 (hemos citado el pasaje al inicio del punto 2).

43 Cf. Conf. I, 4, 4: Quid es ergo Deus meus? Cf. San Agustín, Confesiones, traducción, notas e introducción G. Piemonte, nota I4, p. 5, Colihue, Buenos Aires, 2006. 


\section{Arium ${ }^{44}$. A continuación, comentaremos el pasaje siguiendo el análisis que Hadot propone en Porphyre et Victorinus.}

A diferencia de Agustín, el Victorino presenta en este párrafo a Dios como lo Uno anterior, no sólo a todo lo que es, sino incluso al ser y sus diferentes aspectos formales:

Es lo Uno antes de toda existencia, antes de toda existencialidad y, sobre todo, antes que todo lo inferior, antes que el ser mismo, porque este Uno es antes que el ser. Anterior, pues, a toda entidad, sustancia, subsistencia e incluso anterior a todas las realidades que tienen incluso más potencia ${ }^{45}$.

De los seis términos empleados por el Rétor, la existencia y la existencialidad corresponden al ser puro, mientras los cuatro restantes (el ente, la entidad, la sustancia, la subsistencia) se refieren al ser determinado o substancia ${ }^{46}$.

Hadot advierte que un poco más adelante se expondrá la distinción entre el ser y lo ente en términos casi literalmente idénticos a aquellos empleados en el fragmento quinto del Comentario al Parménides de Porfirio $^{47}$ : el ser anterior a lo ente, esto es, el ser absoluto, "imparticipado",

44 Ad Ar. I B, 49, 9-40: Ante omnia quae vere sunt, unum fuit, sive unalitas, sive ipsum unum, antequam sit ei esse, unum Illud enim unum oportet dicere et intellegere quod nullam imaginationem alteritatis habet, unum solum, unum simplex, unum per concessionem, unum ante omnem exsistentiam, ante omnem exsistentialitatem et maxime ante omnia inferiora, ante ipsum öv; hoc enim unum ante öv; ante omnem igitur essentitatem, substantiam, subsistentiam et adhuc omnia quae potentiora; unum sine exsistentia, sine substantia, sine intellegentia -supra enim haec-immensum, invisibile, indiscernibile universaliter omni alteri et his quae in ipso et his quae post ipsum, etiam quae ex ipso, soli autem sibi et discernibile et definitum, ipsa sua exsistentia, non actu, ut non quiddam alterum sit ab ipso consistentia et cognoscentia sui, inpartile undique, sine figura, sine qualitate neque inqualitate, sine qualitate, quale, sine colore, sine specie, sine forma, omnibus formis carens, neque quod sit ipsa forma qua formantur omnia; et universalium et partilium omnium quae sunt prima causa, omnium principiorum paeprincipium, omnium intellegentiarum praeintellegentia, omnium potentiarum fortitudo, ipsa motione celebrior, ipso statu stabilior -motione enim ineloquibili status est, statu autem ineffabili superelativa motio est- continuatione omni densior, distantia universa altior, definitior universo corpore et maius omni magnitudine, omni incorporali purius, omni intellegentia et corpore penetrabilius, omnium potentissimum, potentia potentiarum, omni genere, omni specie magis totum, vere ôv totum, vere quae sunt omnia ipsum exsistens, omni toto maius, corporali et incorporali, omni parte magis pars, inenarrabili potentia pure exsistens omnia quae vere sunt. Cf. P. Hadot, Porphyre et Victorinus, I, pp. 280-285. La presente traducción del Adversus Arium y las subsiguientes son propias, siguiendo la traducción propuesta por Hadot en Marius Victorinus. Traités théologiques sur la Trinité I, Éditions du Cerf, Paris, I960.

45 Ad Ar. I B, 49, I3-I7: unum ante omnem exsistentiam, ante omnem exsistentialitatem et maxime ante omnia inferiora, ante ipsum öv; hoc enim unum ante öv; ante omnem igitur essentitatem, substantiam, subsistentiam et adhuc omnia quae potentiora.

46 Cf. P. Hadot, Porphyre et Victorinus, I, p. 280 y Ad Ar. I A, 30, I8-26: Quid dicimus esse substantiam? Sicuti sapientes et antiqui definierunt: quod subiectum, quod est aliquid, quod est in alio non esse. Et dant differentiam exsistentiae et substantiae; exsistentia quidem et exsistentialitatem, praeexsistentem subsistentiam sine accidentibus, puris et solis ipsis quae sunt in eo quod est solum esse, quod subsistent; substantiam autem, subiectum cum his ómnibus quae sunt accidentia in ipsa inseparabiliter exsistentibus. 47 Cf. P. Hadot, Porphyre et Victorinus, I, pp. I4I-I42 y Adv. Ar. IV, I9, 4-II: Ante on et ante logos 
"originalmente original"; y el ser coordinado a lo ente, es decir, el ser de "todos aquellos que vienen después de Dios: géneros, especies, etc". La mencionada distinción entre el ser y lo ente la encontraremos luego en Boecio $^{48}$.

Ahora bien, el pasaje del Adversus Arium consagrado a la teología negativa, que estamos comentando, va más allá de esta distinción entre ser y ente, pues lo Uno es anterior incluso al ser. Tal anterioridad de lo Uno debe entenderse como una negación trascendente ${ }^{49}$. En otras palabras, lo Uno no sólo es anterior a lo existente en tanto causa primera de todo lo existente, sino que además es "principio anterior a todo principio" 50 .

De ahí que se niegue la existencia, la substancia, y la inteligencia de lo Uno, no porque carezca de ellas, sino a fin de señalar que el principio de toda existencia, substancia e inteligencia debe ser por sobre éstas. Esta primera negación de los géneros supremos implica toda una serie de negaciones: Dios es sin medida, invisible, indistinto, indivisible, sin figura, sin cualidad, sin color, sin forma. En definitiva, "Dios no puede ser conocido, porque es sin determinación, porque todo conocimiento supone una forma" ${ }^{51}$. Entre esta serie de negaciones hallamos, no obstante, una afirmación: "sólo Él es discernible y definido por su propia existencia, no por un acto, de tal forma que su constitución propia y el conocimiento que Él tiene de sí mismo no sean una cosa diferente de él”'52.

A continuación se advierte que los opuestos móvil-inmóvil, continúo-discontinuo, corpóreo-incorpóreo se predican del principio simultáneamente y en grado superlativo:

Él [lo Uno] es la causa primera de todos los existentes, sean universales

vis et potentia exsistendi illa est quae significatur hoc verbo quod est esse (...). Hoc ipsum esse duobus accipiendum modis, unum ut universale sit et principialiter principale, unde in ceteris esse sit, alioque esse est ceteris quod est omnium post vel generum vel specierum atque huius modi ceterorum. Verum esse primum ita inparticipatum est ut nec unum dici possit nec solum.

48 Cf. P. Hadot, Porphyre et Victorinus, I, pp. 490-492.

49 Cf. Ad Ar. I B, 49, I7-26: unum sine exsistentia, sine substantia, sine intellegentia -supra enim haecimmensum, invisibile, indiscernibile universaliter omni alteri et his quae in ipso et his quae post ipsum, etiam quae ex ipso, soli autem sibi et discernibile et definitum, ipsa sua exsistentia, non actu, ut non quiddam alterum sit ab ipso consistentia et cognoscentia sui, inpartile undique, sine figura, sine qualitate neque inqualitate, sine qualitate, quale, sine colore, sine specie, sine forma, omnibus formis carens, neque quod sit ipsa forma qua formantur omnia. Cf. P. Hadot, Porphyre et Victorinus, I, p. 28I.

$50 \mathrm{Ad} A r$. I B, 49, 28: omnium principiorum praeprincipium.

5I P. Hadot, Porphyre et Victorinus, I, p. 28I.

52 Ad Ar. I B, 49, 20-23: soli autem sibi et discernibile et definitum, ipsa sua exsistentia, non actu, ut non quiddam alterum sit ab ipso consistentia et cognoscentia sui. 
o particulares, el principio anterior a todo principio, la inteligencia anterior a toda inteligencia, la fuerza de todo poder; más móvil que el movimiento mismo, más estable que el mismo reposo -puesto que él es reposo por un movimiento inexpresable y es movimiento por sobre toda expresión por un indecible reposo-; más condensado que todo continuo, más lejano que toda discontinuidad, más acabado que todo cuerpo y más grande que toda grandeza, más impenetrable que todo incorporal y más penetrable que toda inteligencia y que todo cuerpo ${ }^{53}$.

Hadot denomina a esta peculiar predicación del principio de dos opuestos simultáneamente en su grado superlativo la doctrina de la coincidentia de los maxima; en ella se fusionan los métodos de oposición y eminencia: Dios no es ninguna de tales cualidades opuestas, porque es el maximum de cada una al mismo tiempo; es coincidencia de los maxima ${ }^{54}$.

Esta fusión de la vía de oposición y eminencia conduce, en última instancia, a revelar la indeterminación trascendente del principio, -pues toda oposición conlleva determinación-, valiéndose de "una teología afirmativa" 55 cercana a la que encontrábamos en el Hiponense: "es, en un modo absolutamente universal, el ser verdadero, siendo él mismo la totalidad de los verdaderamente existentes ${ }^{56}$, "siendo, por una inefable potencia, sobre un modo absolutamente puro, todos los que verdaderamente son"57.

Sólo a partir de esta teología afirmativa , -advierte Hadot-, podemos comprender cómo es posible la coincidencia de los maxima en el principio: "En el ser puro e indeterminado (del principio), cada determinación es más y mejor ella misma, que cuando luego sea en lo determinado" 58 . El mencionado especialista añade que en el comentario de Porfirio al Parménides encontramos un pasaje similar de lo negativo a lo positivo: "la teología negativa no es sino la expresión de la debilidad de nuestra inteligencia, y ella no debe disimularnos la plenitud del ser

53 Ad Ar. I B, 49, 30-35: [unum] universalium et partilium omnium quae sunt prima causa, omnium principiorum praeprincipium, omnium intellegentiarum praeintellegentia, omnium potentiarum fortitude, ipsa motione celebrior, ipso statu stabilior -motione enim ineloquibili status est, statu autem ineffabili superelativa motio est- continuatione omni densior, distantia universa altior, definitior universo corpore et maius omni magnitudine, omni incorporali purius, omni intelligentia et corpore penetrabilius.

54 P. Hadot, Porphyre et Victorinus, I, p. 282. Cf. Ad. Ar. I B, 49, 30-32. Según Gandillac este método anuncia la coincidentia oppositorum de Nicolás de Cusa (cf. M. de Gandillac, La philosophie de Nicolas de Cuse, pp. I20-I25, Aubier, Paris, I94I).

55 P. Hadot, Porphyre et Victorinus, I, p. 282.

56 Ad. Ar. I B, 49, 36-37: vere ôv totum, vere quae sunt omnia ipsum exsistens.

57 Ad. Ar. I B, 49, 39-40: inenarrabili potentia pure exsistens omnia quae vere sunt.

58 P. Hadot, Porphyre et Victorinus, I, p. 285. 
divino" ${ }^{\prime 2}$.

Para finalizar esta segunda parte dedicada a la teología negativa del Victorino, presentamos el siguiente pasaje de su Carta a Cándido, en el cual se advierte que la causa de lo que es y de lo que no es, es anterior y por sobre ambos; por consiguiente, la causa no puede ser inteligida ni en lo que es, ni en lo que no es, sino en la "ignorancia:

Y es lícito decir, impío es entender y llamar ón a la causa de aquello que es. Pues la causa es antes de aquello de lo cual es causa. Por tanto, Dios es por sobre ón y según el modo de lo que es por sobre, Dios es llamado mè ón, no por privación de la totalidad de lo que es, sino en cuanto otro ón ${ }^{60}$.

Ahora bien, ¿qué es este tò mè ón por sobre tò ón? Lo que no es inteligido en cuanto ón ni en cuanto mè ón, sino en cuanto inteligible en la ignorancia, porque (es) ón y porque (es) no ón $n^{61}$.

Pues si produjo tò ón, verdadero es decir que quien es por sobre tò ón habrá engendrado tò ón, porque esparció la semilla desde sí mismo más bien que desde la nada. Pues lo que es por sobre ón es ón escondido. En verdad, la generación es la manifestación de lo escondido ${ }^{62}$.

Así, la causa de lo que es y de lo que no es sólo puede ser inteligida en la "ignorancia", pues el principio reúne en tanto causa lo que es y lo que no es. De ahí que la cita termine advirtiendo que, si bien la causa de lo que es no puede carecer de entidad, su condición ontológica trasciende y funda a la de lo que es. Acentuando esta trascendencia, Victorino lo llama "ón escondido". De esta forma se niega que podamos comprehender la naturaleza del principio a partir de lo que proviene de él, aunque en ello se manifieste algún aspecto de éste.

59 P. Hadot, Porphyre et Victorinus, I, p. 283. Cf. Porfirio, In Parm. IV, 27 y ss.

6o Ad Cand.4: et non licet dicere, nefas est intelligere, eorum quae sunt causam ón appellare. Causa enim prior est ab his quorum causa est. Supra ón igitur deus est, iuxta quod supra est, mè ón deus dicitur, non per privationem universo eius quod sit, sed ut aliud ón. Seguimos aquí y en las dos siguientes citas de la Carta a Cándido la traducción de C. D'Amico en C. D'Amico (ed.), Todo y nada de todo. Selección de textos del neoplatonismo latino medieval, pp. 38-43, Winograd, Buenos Aires, 2008.

6I Ad Cand. I4: Quid autem tò mè ón super tò ón est? Quod non intellegatur ut ón neque ut mè ón, sed ut in ignoratione intelligibile, quoniam ón et quoniam non ón.

62 Ad Cand. I4: Si enim tò ón produxit, verum est dicere, quoniam a semet ipso, qui super tò ón est, tò ón generavit quam de nihilo. Quo denim supra ón est, absconditum ón est. Absconditi vero manifestatio generatio est. 


\section{Coincidencias y diferencias de ambas teologías negativas}

Esperamos haber contribuido en la comprensión de dos concepciones teológicas que resultarán tan significativas para la historia de la filosofía. En relación a la de Agustín, hemos procurado resaltar algunos de los elementos provenientes de la tradición neoplatónica presentes en su concepción teológica. En efecto, si bien el Hiponense no cuenta con un conocimiento tan directo y profundo del pensamiento neoplatónico como Mario Victorino, pueden descubrirse en su concepción teológica elementos provenientes de la mencionada tradición: su preferencia por la negación, su culminación en una "docta ignorantia"63, y sobre todo, la razón ontológica por la cual se opta por tal metodología: si todo conocer consiste en desentrañar la forma de lo conocido, Dios resulta incognoscible en tanto escapa a toda determinación ${ }^{64}$.

En relación a la concepción teológica de Victorino, la cual preanuncia ya las teologías negativas de Dionisio Areopagita, Máximo el Confesor, Juan Escoto Eriúgena y Nicolás de Cusa ${ }^{65}$, la constatación de la importancia que los principios de la apophasis adquieren en la concepción teológica de Agustín, y el descubrimiento de los mencionados elementos provenientes de la tradición neoplatónica asimilados en dicha concepción teológica, muestran la influencia de la tradición neoplatónica en la obra del Hiponense. Ambos, esto es, los principios de la apophasis junto con los mencionados elementos neoplatónicos, no son suficientes para responder a nuestra hipótesis inicial, -si y en qué medida Victorino pudo haber sido una de las fuentes neoplatónicas que influyen en la teología negativa agustiniana-, pero muestran su plausibilidad.

Ahora bien, un inicio de respuesta a esta cuestión la encontramos al comparar la teología negativa del Hiponense con la del Rétor. A pesar de haber advertido una importante diferencia entre ambas teologías, -ya señalada a su vez por Carabine, quien sigue a Gilson-: "aunque Agustín entiende al ser de Dios como ser absolutamente trascendente, no adopta el pensamiento más explícitamente plotiniano del Victorino, donde Dios es entendido como mè ón porque es próon"66; tres puntos parecen

\footnotetext{
63 Aunque otorgándole un sentido nuevo y original, Nicolás de Cusa encontrará resplandeciendo de diversa manera su intuición de la "docta ignorantia" en otros pensadores pertenecientes a la tradición neoplatónica, entre los que explícitamente menciona a Agustín de Hipona (Cf. N. de Cusa, Apol. doc. ig. (h. II, n. I7-I8) ).

64 Cf. De Trin. V, 2, 3 y P. Hadot, Porphyre et Victorinus, I, p. 28I.

65 Cf. É. Gilson, La filosofía en la Edad Media, p.I23, Gredos, Madrid, 1999.

66 D. Carabine, The Unknown God, p. 267 y É. Gilson, La filosofía en la Edad Media, pp., Gredos, Madrid, 200I.
} 
vincular la concepción teológica de Agustín con la del Victorino: I) sólo el principio es discernible y definido por su propia existencia; 2) la anterioridad del principio respecto a toda oposición. En particular, el Obispo de Hipona señala, como el Rétor, que en Dios la actividad se identifica con el reposo ${ }^{67}$. No obstante, mientras la doctrina de los maxima conduce en última instancia hacia una teología que busca poner de manifiesto la indeterminación trascendente del principio, el Hiponense procura, mediante la concepción de Dios como el mismo ser, resaltar su condición ontológica absolutamente simple e infinita ${ }^{68}$.3) De ahí que ambos pensadores propongan un modo de conocer más adecuado para aproximarse a la naturaleza divina: el saber de la docta ignorantia, que, en tanto ha reconocido su anterioridad, no busca determinarlo en el ámbito de los opuestos, sino simplemente señalar su sobreeminencia.

cc) (†) Esta obra está bajo una licencia de Creative Commons

Reconocimiento-No-Comercial-Compartir Igual 4.0 Internacional.

67 Cf. Conf. XIII, 37, 52; In Io. ev. XVII, I4, y San Agustín, Confesiones, traducción, notas e introducción G. Piemonte, nota I462, p. 434.

68 Cf. É. Gilson, "L'infinité divine chez saint Augustin”, en Augustinus Magister I (I954), pp. 569574 . 
